\title{
Risk Factors for Brucella Seroprevalence in Peri-Urban Dairy Farms in Five Indian Cities
}

\author{
Johanna F. Lindahl 1,2,3®, Jatinder Paul Singh Gill ${ }^{4}$, Razibuddin Ahmed Hazarika ${ }^{5}$, \\ Nadeem Mohamed Fairoze ${ }^{6}$, Jasbir S. Bedi ${ }^{4}$, Ian Dohoo ${ }^{7}$, Abhimanyu Singh Chauhan ${ }^{8,9}$, \\ Delia Grace ${ }^{1}$ and Manish Kakkar ${ }^{8, *}$ \\ 1 Department of Biosciences, International Livestock Research Institute, Nairobi 00100, Kenya; \\ J.lindahl@cgiar.org (J.F.L.); D.Randolph@cgiar.org (D.G.) \\ 2 Department of Clinical Sciences, Swedish University of Agricultural Sciences, PO Box 7054, \\ SE-750 07 Uppsala, Sweden \\ 3 Zoonosis Science Centre, Department of Medical Biochemistry and Microbiology, Uppsala University, \\ Po Box 582, SE-751 23 Uppsala, Sweden \\ 4 Guru Angad Dev Veterinary and Animal Sciences University, Ludhiana 141004, Punjab, India; \\ gilljps@gmail.com (J.P.S.G.); bedijasbir78@gmail.com (J.S.B.) \\ 5 Department of Veterinary Public Health, Assam Agricultural University, Khanapara Campus, \\ Guwahati-781022, India; rah1962@rediffmail.com \\ 6 Department of LPT, Veterinary College, Karnataka Veterinary Animal \& Fisheries Sciences University \\ Bangalore, Bangalore 560024, India; prof.nadeem@gmail.com \\ 7 Atlantic Veterinary College, University of Prince Edward Island, Charlottetown, C1A 4P3, Canada; \\ dohoo@upei.ca \\ 8 Public Health Foundation India, Gurgaon 122002, India; abhimanyu.hm@gmail.com \\ 9 Department of Public Health Sciences, Faculty of Medicine, University of Liège, 4000 Liege, Belgium \\ * Correspondence: manish.kakkar@phfi.org; Tel.: +91-124-4781400
}

Received: 15 March 2019; Accepted: 17 April 2019; Published: 22 April 2019

\begin{abstract}
Brucellosis is endemic among dairy animals in India, contributing to production losses and posing a health risk to people, especially farmers and others in close contact with dairy animals or their products. Growing urban populations demand increased milk supplies, resulting in intensifying dairy production at the peri-urban fringe. Peri-urban dairying is under-studied but has implications for disease transmission, both positive and negative. In this cross-sectional study, five Indian cities were selected to represent different geographies and urbanization extent. Around each, we randomly selected 34 peri-urban villages, and in each village three smallholder dairy farms (defined as having a maximum of 10 dairy animals) were randomly selected. The farmers were interviewed, and milk samples were taken from up to three animals. These were tested using a commercial ELISA for antibodies against Brucella abortus, and factors associated with herd seroprevalence were identified. In all, 164 out of 1163 cows $(14.1 \%$, $95 \%$ CI $12.2-16.2 \%)$ were seropositive for Brucella. In total, 91 out of 510 farms $(17.8 \%$, 95\% CI 14.6-21.4\%) had at least one positive animal, and out of these, just seven farmers stated that they had vaccinated against brucellosis. In four cities, the farm-level seroprevalence ranged between $1.4-5.2 \%$, while the fifth city had a seroprevalence of $72.5 \%$. This city had larger, zero-grazing herds, used artificial insemination to a much higher degree, replaced their animals by purchasing from their neighbors, were less likely to contact a veterinarian in case of sick animals, and were also judged to be less clean. Within the high-prevalence city, farms were at higher risk of being infected if they had a young owner and if they were judged less clean. In the low-prevalence cities, no risk factors could be identified. In conclusion, this study has identified that a city can have a high burden of infected animals in the peri-urban areas, but that seroprevalence is strongly influenced by the husbandry system. Increased intensification can be associated with increased risk, and thus the practices associated with this, such as artificial insemination, are also associated with increased risk. These results may be important to identify high-risk areas for prioritizing interventions and for policy decisions influencing the structure and development of the dairy industry.
\end{abstract}


Keywords: zoonoses; prevalence; Brucella abortus; urban livestock keeping; smallholder farming

\section{Introduction}

Infectious diseases cause a major burden on both human health and society as a whole. Zoonotic diseases inflict a double burden, since they also affect animal health, with associated costs and reduced productivity. Brucellosis is a very common but frequently neglected zoonosis that occurs globally, except for in a few countries that have managed to eradicate it, and the disease is often underreported and uncontrolled in low and middle-income countries, which may have the highest burden of the disease [1-4].

The disease can be caused by different bacteria of the genus Brucella, of which most species are pathogenic to multiple mammals, including cattle and humans [5,6]. Cattle are most frequently infected by Brucella abortus or Brucella melitensis [5,6]. These bacteria cause a chronic infection with preferred localization in the reproductive system, where they can cause abortion in pregnant cows or other reproductive problems, as well as reduced milk production in lactating animals and orchitis in bulls [1,7]. Although most infected animals only abort once, they may remain infected their entire life [8]. After the first abortion, as well as in non-pregnant animals, the disease can be asymptomatic [5]. Infected male cattle can spread the disease sexually, and both sexes may become infertile. Joint hygromas are another common manifestation of brucellosis [3].

Milk consumption has been increasing in low and middle-income countries, a trend likely to continue as the demand for animal-source food trends upwards due to population growth, changing lifestyles, and increasing wealth [9]. In India, the large vegetarian population increases the dependence on dairy products for high quality proteins. India has the world's largest dairy herd at around 300 million and is the world's leading milk producer, contributing around $17 \%$ of the world's total milk production, with more than 70 million households engaged in milk production $[10,11]$. Milk consumption is higher in urban areas and while the majority of the Indian population still live in rural areas, urbanization is increasing. Cities require a constant supply of fresh milk, and peri-urban dairy production plays an important role in meeting this demand.

The health of livestock, humans and livelihoods are closely linked, with zoonotic diseases such as brucellosis causing not only human and animal morbidity, but also reduced animal production and hence reduced incomes [12,13]. In India, awareness of brucellosis is low among livestock-keepers and healthcare staff, and because of the non-specific symptoms and the limited availability of laboratory facilities in many rural hospitals, diagnosis is seldom feasible [14,15]. Multiple studies have found seropositivity in humans in India, indicating the need to have an OneHealth approach for controlling this disease [16].

\section{Materials and Methods}

\subsection{Ethical Approval}

The study received ethical approval from the ethics committee of the Public Health Foundation of India [TRC-IEC-219/14, 27 May 2014; amended 12 October 2015]. Ethical approval was also obtained by Institutional Ethics Committees of Guru Angad Dev Veterinary and Animal Sciences University (GADVASU), Assam Agricultural University (AAU), Karnataka Veterinary, Animal and Fisheries Sciences University (KVAFSU), Rajasthan University of Veterinary and Animal Sciences (RAJUVAS) and School of Biotechnology, Kalinga Institute of Industrial Technology (KSBT) at the Ludhiana, Guwahati, Bangalore, Udaipur and Bhubaneswar study sites, respectively. Before a farmer was interviewed, they were informed about the purpose of the study and gave their consent to participate. 


\subsection{Farm Selection}

Five Indian cities were selected purposively to represent different parts of the country (Figure 1). Peri-urban was defined as within $5 \mathrm{~km}$ of the official city boundaries, and all villages in that circle were mapped. For the purpose of this study, smallholder farms were defined as a dairy farm with a herd size of less than 10 cattle/buffaloes at the time of the survey and at least one milking animal, with dairy constituting a source of livelihood with or without domestic consumption. A systematic selection of 34 of these villages was done by identifying the proportion that needed to be sampled, and then systematically choosing these in a clockwise fashion around the city. The selected villages were then visited to identify all farms, using local village leaders as guides. The methodology of the creation of this sampling frame has been described elsewhere [17]. Out of this sampling frame, three smallholder farmers per village were randomly selected.

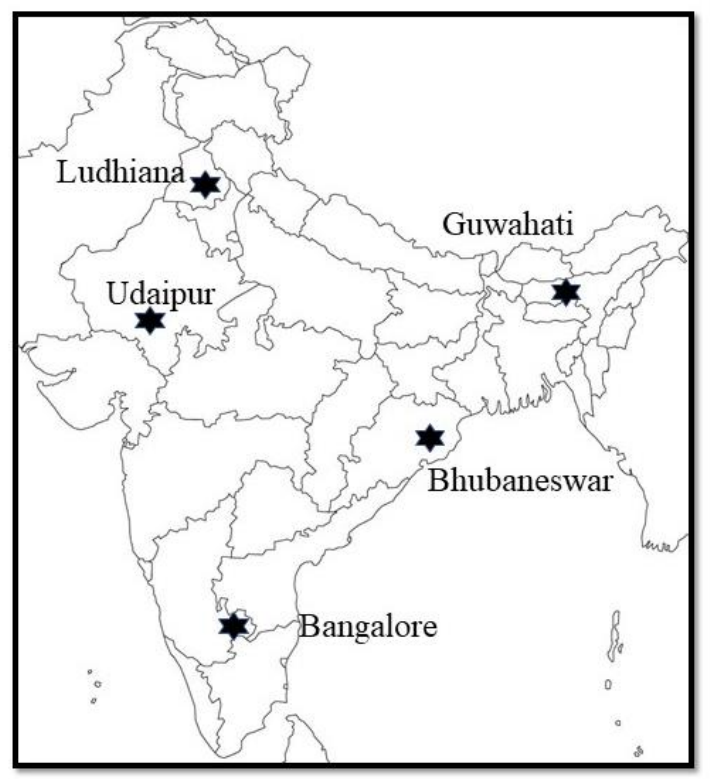

Figure 1. Location of selected cities in India.

\subsection{Data Collection}

Data collection was done between June 2015 and January 2016. A questionnaire was developed and piloted on farms in each site before starting the sampling. The tool was uploaded into electronic format and data collection was conducted using tablets, from which the data was uploaded into a central server. Data was collected by different data collection teams in each city, but all teams were trained by the same trainers, who joined in the first days of data collection. The data was collected through interviews in the local language, after the participants had been read the information about the project and given their written consent. Observations about cleaning practices and hygienic status were done during milking using an observation checklist. Cleanliness and drainage scores were standardized using pictures to guide the grading, and the scoring was assessed during the training to make sure it was consistent. Knowledge about antibiotics was assessed based on if the farmer reported to know the word (in the local language).

\subsection{Sample Collection}

In each farm, up to three milking cows or buffaloes were selected for sampling. In the $33 \%$ of farms where the number of milking cattle exceeded three, all cows were given a unique number, and then three numbers were selected randomly. The data collection teams were trained on aseptic collection of milk from the selected cows, and $40 \mathrm{~mL}$ of milk was collected in sterile vials and immediately kept chilled until they were transported to the laboratory on the same day of collection. The samples 
were thereafter stored in deep freezer at $-80^{\circ} \mathrm{C}$. Samples were kept frozen when transported to the laboratory of microbiology at GADVASU and stored at $-80^{\circ} \mathrm{C}$ until analysis.

\subsection{Serological Analysis}

Milk was analyzed for the presence of antibodies using a commercial indirect enzyme-linked immunosorbent assay (iELISA) developed for use with milk samples (IDEXX Brucellosis Milk X2 Ab Test, IDEXX, Westbrook, ME, USA). The protocol of the manufacturer was followed, and all samples were done in duplicates. In brief, $50 \mu \mathrm{L}$ of milk was diluted into $200 \mu \mathrm{L}$ of sample diluent on a microplate precoated with Brucella lipopolysaccharide (LPS). The plate was incubated for $90 \mathrm{~min}$, before being washed and the subsequent addition of conjugated anti-bovine IgG antibodies. After $30 \mathrm{~min}$ of incubation and washing, the tetramethylbenzidine (TMB) substrate was added and incubated for $20 \mathrm{~min}$ before the stop solution was added and the plate read at $450 \mathrm{~nm}$.

The ratio of the optical density of the samples (mean) to the mean positive control was calculated after subtracting the mean of the negative controls from both. A ratio of above $55 \%$ was considered positive, while between 45 and $55 \%$ was considered suspected positive. In the analysis, only one sample was suspected positive, and since all other animals tested at the same farm were also positive, this animal is considered positive in the analyses and results. The specificity for this kit used on milk samples has been found to be very high [18], and a meta-analysis suggest a specificity of $96 \%$ for ELISA conducted on milk [19].

\subsection{Data Analysis}

An initial screening of all information collected was carried out with only the variables listed in Table 1 being retained for analysis, after identifying the variables with potential causal association with brucellosis. Analysis of the retained data proceeded in four steps. First, multiple correspondence analysis (MCA) was used to investigate relationships among all the predictors recorded. All predictors were initially recoded to di- or trichotomous variables. An MCA was carried out using all predictors and those having a contribution to either the first or second dimension that exceeded 0.02 were retained. The process was repeated sequentially with the required contribution being raised by 0.01 at each step (to a maximum of 0.06). At this point, the six variables that best explained the information content of the full set had been identified and these were plotted on a two-dimensional MCA plot (Figure 2).

One site (Guwahati) had a dramatically higher farm prevalence (72\%) than the other four sites $(4 \%)$, so the second step in the analysis was to evaluate the unconditional associations between each of the predictors and a variable representing Guwahati compared to the other sites. Either two-sample $t$-tests or cross-tabulations with chi-square statistics were used to determine if the regions were different. Results are presented in Table 1. Guwahati was also added as a supplemental variable (s51 vs s50 in Figure 2) to the MCA plot in Figure 2 to show which predictors were most associated with Guwahati vs other sites.

The third step was to use logistic regression models to identify factors associated with the risk of a farm being Brucella spp. positive within Guwahati, using backward elimination among variables with unconditional associations with $p<0.15$. A random effect for village was included in all models. The linearity of continuous predictors was evaluated using lowess smoothed curves and a quadratic term was added to the model if there was significant evidence of curvature in the relationship. Initially, unconditional associations were determined with predictors having $p<0.15$ retained for further consideration. A manual backward elimination was used to remove non-significant (at $p>0.05$ ) predictors. Age of farmer and farm size (number of animals) were forced into all models as potential confounders. In addition to age and number of animals, two factors (cleanliness of floor and level of vaccination) were identified as potentially important. An MCA plot was generated (using trichotomous versions of each of the predictors) with Brucella spp. added as a supplemental variable to the final plot to see which predictors were generally associated with being Brucella spp. positive or negative. 
Table 1. Potential risk factors for brucellosis given as either mean (standard deviation), or proportion (95\% confidence interval).

\begin{tabular}{|c|c|c|c|c|c|c|c|}
\hline & All Sites & Guwahati & Bangalore & Bhubaneswar & Ludhiana & Udaipur & p-Value * \\
\hline Age of farmer & $46.2(12.3)$ & $43.9(12.9)$ & $44.8(13.2)$ & $51.1(10.8)$ & $46.6(12.7)$ & $44.6(10.2)$ & 0.035 \\
\hline Female respondents & $21.8 \%(18.3-25.6)$ & $15.7 \%(9.2-24.2)$ & $41.2 \%(31.5-51.4)$ & $11.8 \%(6.2-19.6)$ & $14.7 \%(8.5-23.1)$ & $25.5 \%(17.4-35.1)$ & 0.096 \\
\hline Illiterate respondents & $35.4 \%(31.0-39.9)$ & $51.1 \%(40.2-61.9)$ & $41.1 \%(30.8-52.0)$ & $23.5 \%(15.7-33.0)$ & $15.7 \%(8.6-25.3)$ & $44.9 \%(34.8-55.3)$ & 0.001 \\
\hline Number of dairy animals & $7.7(4.0)$ & $10.3(4.1)$ & $5.4(2.7)$ & $8.1(3.6)$ & $7.2(3.7)$ & $7.5(4.0)$ & $<0.001$ \\
\hline Zero-grazing & $53.3 \%(48.9-57.7)$ & $95.1 \%(88.9-98.3)$ & $9.8 \%(4.8-17.2)$ & $4.9 \%(1.6-11.1)$ & $93.1 \%(86.4-97.2)$ & $63.7 \%(53.6-73.0)$ & $<0.001$ \\
\hline Using AI & $76.0 \%(72.1-79.7)$ & $92.2 \%(85.1-96.6)$ & $98.0 \%(93.1-99.8 \%)$ & $47.5 \%(37.5-57.7)$ & $69.6 \%(59.7-78.3)$ & $72.5 \%(62.8-80.9)$ & $<0.001$ \\
\hline Purchasing cows from neighboring farms & $57.6 \%(52.8-62.3)$ & $98.9 \%(94.0-100)$ & $71.7 \%(57.7-83.2)$ & $21.1 \%(13.4-30.6)$ & $34.4 \%(24.9-45.0)$ & $69.0 \%(59.0-77.9)$ & $<0.001$ \\
\hline Dirty floors in cow sheds & $11.1 \%(8.5-14.2)$ & $24.8 \%(16.7-34.3)$ & $11.0 \%(5.6-18.8)$ & $10.8 \%(5.5-18.5)$ & $6.1 \%(2.3-12.7)$ & $3.0 \%(0.6-8.4)$ & $<0.001$ \\
\hline Well-drained floors & $19.8 \%(16.4-23.6)$ & $8.9 \%(4.2-16.2)$ & $22.8 \%(15.2-32.5)$ & $23.5 \%(15.7-33.0)$ & $35.4 \%(26.0-45.6)$ & $8.9 \%(4.2-16.2)$ & 0.007 \\
\hline Never vaccinate animals & $15.5 \%(12.4-18.9)$ & $25.5 \%(17.4-35.1)$ & $0 \%(0-3.6)$ & $2.0 \%(0.2-6.9)$ & $7.8 \%(3.4-14.9)$ & $42.42 \%(32.4-52.3)$ & $<0.001$ \\
\hline Vaccinate young animals routinely & $26.7 \%(22.9-30.7)$ & $61.8 \%(51.6-71.2)$ & $2.9 \%(0.6-8.4)$ & $44.1 \%(34.3-54.3)$ & $0 \%(0-3.6)$ & $24.5 \%(16.5-34.0)$ & $<0.001$ \\
\hline Records of sick animals & $11.6 \%(8.0-14.7)$ & $0 \%(0-3.6)$ & $8.8 \%(4.1-16.1)$ & $24.5 \%(16.5-34.0)$ & $1.0 \%(0-5.3)$ & $23.5 \%(15.7-33.0)$ & $<0.001$ \\
\hline Alpha score for cleaning routines & $2.19(0.28)$ & $2.14(0.23)$ & $2.10(0.28)$ & $2.16(0.08)$ & $2.06(0.13)$ & $2.50(0.34)$ & 0.034 \\
\hline Alpha score for observed hygiene & $0.32(0.28)$ & $0.10(0.11)$ & $0.31(0.21)$ & $0.60(0.31)$ & $0.25(0.21)$ & $0.35(0.23)$ & $<0.001$ \\
\hline Regular health checks & $23.9 \%(20.3-27.9)$ & $3.9 \%(1.1-9.7)$ & $14.7 \%(8.5-23.1)$ & $33.3 \%(24.3-43.4)$ & $46.1 \%(36.2-56.2)$ & $21.6 \%(14.0-30.8)$ & $<0.001$ \\
\hline $\begin{array}{l}\text { Let veterinarian check animals before } \\
\text { purchase, or test the animal }\end{array}$ & $25.9 \%(22.1-29.9)$ & $-8.4)$ & $35.3 \%(26.1-45.4)$ & $58.8 \%(48.6-68.5)$ & $9.8 \%(4.8-17.3)$ & $22.6 \%(14.9-31.9)$ & $<0.001$ \\
\hline Quarantine new animals & $24.6 \%(20.8-28.4)$ & $17.7 \%(10.8-26.4)$ & $19.6 \%(12.4-28.6)$ & $41.4 \%(31.6-51.8)$ & $19.6 \%(12.4-28.6)$ & $24.5 \%(16.5-34.0)$ & 0.074 \\
\hline
\end{tabular}

* Comparing Guwahati with the four other sites. 


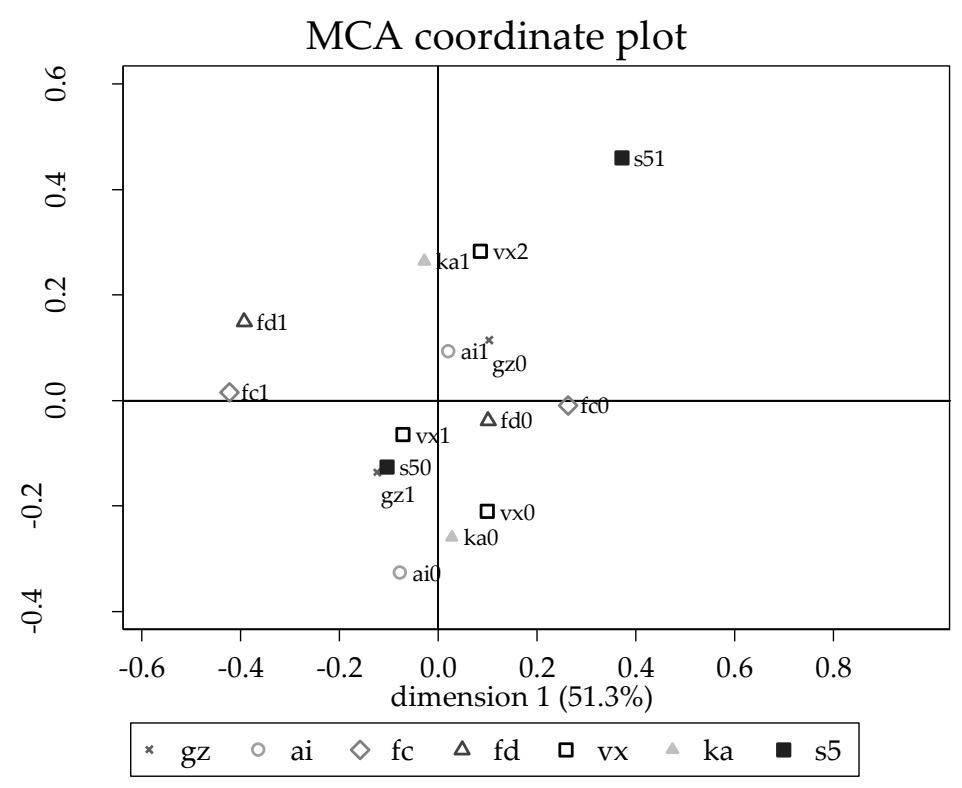

Figure 2. Multiple correspondence analysis (MCA) plot for the factors associated with the high seroprevalence site. $\mathrm{Gz}=$ grazing, where gz0 is zero-grazing and gz1 is grazing. Ai = artificial insemination, where ai0 is no artificial insemination and ai1 is use of artificial insemination. $\mathrm{Fc}_{\mathrm{C}}=$ floor cleanliness, where $\mathrm{fc} 0$ is clean or moderately clean floor and $\mathrm{fc} 1$ is dirty floor. $\mathrm{Fd}=$ drainage, where $\mathrm{fd} 0$ equals insufficient drainage and $\mathrm{fd} 1$ is good drainage. $\mathrm{Vx}=$ vaccination, where $\mathrm{vx} 0$ means no vaccination done, vx1 means vaccination when there is an outbreak or when given free vaccines, and vx2 means vaccinating animals as young. $\mathrm{Ka}=$ knowledge about antibiotics, where $\mathrm{ka} 0$ is no knowledge and ka1 is the farmer reporting to know about antibiotics. S5 = site Guwahati, where s50 means any other site and s51 means Guwahati.

Finally, the model building process was repeated to determine which factors most influenced the risk of being Brucella spp. positive in sites 1 to 4 . Only two predictors (farm size and use of Haemorrhagic septicemia vaccine) had unconditional associations with $p<0.15$, but neither of these was significant in a final model so no results are presented.

\section{Results}

\subsection{Brucella Seroprevalence}

In total, 164 out of 1163 cows (14.1\%, 95\% CI 12.2-16.2\%) were seropositive for Brucella.

A farm was considered positive for Brucella if at least one out of the three tested animals tested positive. In total, 91 farms out of $510(17.8 \%, 95 \%$ CI $14.6 \%-21.4 \%)$ had at least one positive animal (see Table 2), and out of these, 23 farms had two positive animals and 25 (all in Guwahati) had all three animals positive. There were large differences in farm prevalence between the five different cities (Table 2). Guwahati had significantly higher seroprevalence $(p<0.001)$ than the other sites, and the odds ratio for a farm being positive in Guwahati was 44.4 (95\% CI 7.5-113.2) times higher than in Udaipur and 138.9 (95\% CI 32.0-602.3) times higher than in Bhubaneswar. 
Table 2. Farm level Brucella seroprevalence (95\% confidence interval) in the five different cities.

\begin{tabular}{ccc}
\hline & Brucella Farm Positivity & Brucella Farm Positivity Excluding Farms with Vaccination \\
\hline Bangalore & $2.9 \%(0.6-8.4)$ & $3.0 \%(0.6-8.6)$ \\
Bhubaneswar & $2.0 \%(0.2-6.9)$ & $1.4 \%(0-7.4)$ \\
Guwahati & $73.5 \%(63.9-81.8)$ & $72.5 \%(62.5-81.0)$ \\
Ludhiana & $4.9 \%(1.6-11.1)$ & $4.3 \%(1.2-10.6)$ \\
Udaipur & $5.9 \%(2.2-12.4)$ & $5.2 \%(1.7-11.6)$ \\
Overall & $17.8 \%(14.6-21.34)$ & $18.3 \%(14.8-22.1)$ \\
\hline
\end{tabular}

\subsection{Risk Factor Analyses for Herds with No Previous Vaccination}

The presence of different stipulated risk factors varied across the five cities. After exclusion of farms that reported having vaccinated against Brucella earlier, 460 farms from 162 villages in five sites (geographic regions) were included. Missing values were observed in 0 to $15.6 \%$ of observations within a variable and $62 \%$ of farms had complete data for all variables. Brucella prevalence ranged from 1.4 to $5.2 \%$ across four sites, while the prevalence in Guwahati was $72.5 \%$.

The MCA analysis for investigating relationships among predictors identified pasture grazing, use of artificial insemination (AI) (vs natural breeding), routine (vs irregular) vaccination, floor cleanliness, adequacy of floor drainage, and owner knowledge of antibiotics as the six variables most useful in discriminating among farms. Floor cleanliness and drainage contributed most to the first dimension (explaining 51.3\% of inertia (information) in the data) while level of vaccination, knowledge of antibiotics and AI contributed most to the second dimension ( $45.0 \%$ of inertia). Farmers that had knowledge of antibiotics also used routine vaccination, and they tended to be farms that did not pasture (graze) animals but did use AI. Farms with good floor cleanliness also had good floor drainage.

Evaluation of unconditional associations between the recorded predictors and Guwahati vs the other sites showed many statistically significant differences. With the exception of three of the four demographic variables and the quarantining of new entries into the herd, all predictors showed significant differences at $p<0.05$. Compared to the other cities, Guwahati had larger non-pastured herds, used AI for breeding, purchased their replacements from neighbors, were less likely to have good stable cleanliness or drainage scores, were more likely to have dirty stable floors, had a lower composite hygiene score, and were less likely to have veterinarians regularly check their animals or check animals before purchase. However, they were more likely to use routine vaccinations of young animals and to know what antibiotics were.

\subsection{Risk Factors for Brucella Seropositivity in Guwahati}

In addition to age and herd size, which were included as potential confounders, two management factors (floor cleanliness and level of vaccine use) were identified as being associated with Brucella spp. A multiple correspondence analysis (MCA) plot was generated (using trichotomous versions of each of the predictors) with Brucella spp. added as a supplemental variable to the final plot to see which predictors were generally associated with being Brucella spp. positive or negative (Figure 3). Being Brucella positive (B1) was most common in farms that had a younger age owner (ag0 or ag1) and had a lower floor cleanliness scores ( $\mathrm{fc} 1$ or $\mathrm{fc} 2$ ). Being Brucella negative (B0) was most strongly associated with the cleanest floors ( $f_{c} 3$ ) and the smallest herds (na0). Table 3 shows the odds ratios associated with seropositivity for risk factors in Guwahati from the multivariable model. The high village level variance indicates a very high intra-cluster correlation. 


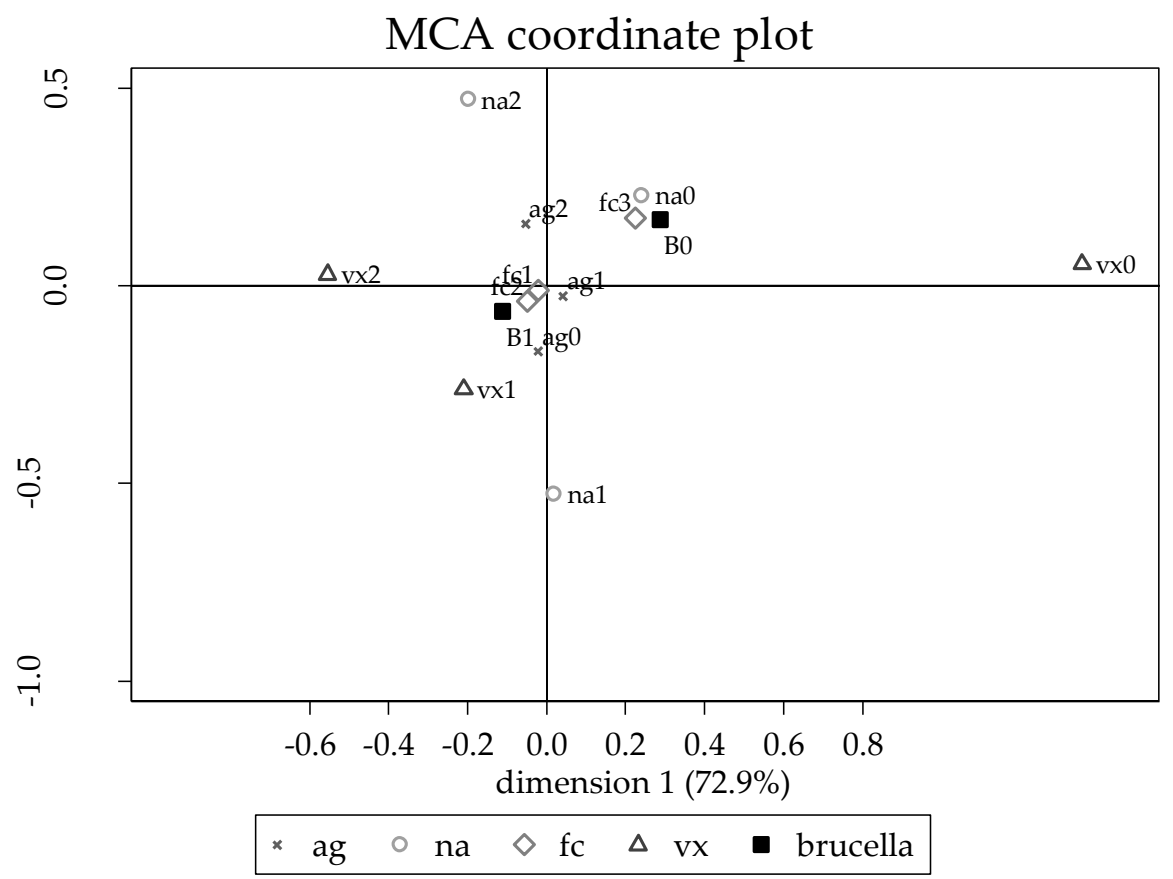

Figure 3. MCA plot of risk factors for Brucella seropositivity in Guwahati, India. Ai = Artificial insemination, where ai0 is no artificial insemination and ai1 is use of artificial insemination. $\mathrm{Na}=$ number of animals, where na0 is less than 7 animals and na1 is $7-10$ animals. Fc $=$ floor cleanliness, where fc0 is clean or moderately clean floor and $\mathrm{fc} 1$ is dirty floor. $\mathrm{Vx}=$ vaccination, where vx0 means no vaccination done, vx1 means vaccination when there is an outbreak or when given free vaccines, and vx2 means vaccinating animals as young. $\mathrm{B}=$ Brucella, where $\mathrm{B} 0=$ seronegative farm and $\mathrm{B} 1=$ seropositive farm.

Table 3. Risk factors for Brucella seropositivity within Guwahati, India, using a mixed logistic regression model.

\begin{tabular}{|c|c|c|c|c|}
\hline Risk Factor & Odds Ratio & 95\% Confidence Interval & Standard Error & $p$-Value \\
\hline Farmer age (year) & 0.96 & $0.90-1.02$ & 0.03 & 0.20 \\
\hline \multicolumn{5}{|l|}{ Floor cleanliness } \\
\hline Clean & Reference & & & \\
\hline Average & 11.6 & $1.29-105.18$ & 13.1 & 0.03 \\
\hline Dirty & 42.8 & $1.87-978.57$ & 68.3 & 0.02 \\
\hline \multicolumn{5}{|l|}{ Vaccination } \\
\hline No vaccination & Reference & & & \\
\hline Vaccinate irregularly & 44.1 & $0.73-2669.57$ & 92.3 & 0.07 \\
\hline Vaccinate routinely & 12.8 & $1.40-116.80$ & 14.4 & 0.02 \\
\hline Number of animals & 1.0 & $0.85-1.30$ & 0.4 & 0.7 \\
\hline Quadratic term of number of animals & 0.95 & $0.90-0.999$ & 0.02 & 0.05 \\
\hline Constant & 2.2 & $0.05-91.5$ & 4.1 & \\
\hline Village level variance & 4.2 & $0.65-26.84$ & 4.0 & \\
\hline
\end{tabular}

\subsection{Risk Factors for Brucella Seropositivity in Bangalore, Bhubaneswar, Ludhiana, and Udaipur}

Logistic models were also used to investigate risk factors for Brucella spp. positivity within the low-prevalence sites. However, no risk factors had significant associations, so no results are presented.

\section{Discussion}

This study found high variation in the seroprevalence between the different peri-urban sites. In general, our findings were comparable with the literature on bovine brucellosis in India. A recent review concluded that most studies using probabilistic sampling and not targeting cows with a clinical history suggesting brucellosis, reported a prevalence of $5-12 \%$, which is above what was detected 
in the four other cities but considerably less than that we found in Guwahati [20]. While this study could not identify many risk factors in the peri-urban farms, it was found that keeping floors clean was important. Risk of Brucella exposure was also associated with herd size, which has been shown previously [21-24]. Vaccinating (for other diseases than brucellosis), either routinely or when there were vaccination campaigns in the face of outbreaks or vaccines provided for free, was associated with a higher risk of exposure, which could potentially be explained as farmers with more experience with disease being more positive to vaccination.

The peri-urban seroprevalence in Ludhiana, Punjab, was lower than previously reported in the state. Here $21 \%$ and $18 \%$ seroprevalence was found by Aulakh et al. [25] and Ul-Islam et al. [26]. Gill et al. [23] and Dhand et al. [27] also found more than 10\% prevalence in cattle. This may indicate that reducing prevalence is associated with better control or changing husbandry, or may reflect a more systematic approach to sampling in our study, which focused only on smallholder peri-urban dairying.

The high seropositivity in Guwahati is in accordance with results from the same area using a milk ring test, where $88 \%$ of farms were found positive [28]. Chakraborty et al. [29] found $60 \%$ seropositivity among lactating cows in Guwahati, whereas Gogoi et al. [30] found 30\% seroprevalence in Kamrup metropolitan district of Guwahati. It is worth noting that Renukaradhya et al. [31] did not find any seropositive animals in Assam, using their own developed ELISA. Given the results of our research and the earlier research from the state, it seems that the peri-urban belt around Guwahati may have a higher than average burden of brucellosis. Brucellosis in humans has not been extensively studied, but in one previous study, three (all with animal husbandry background) out of 52 humans tested positive in Assam [32]. In people with animal contact, more than $24 \%$ seropositivity was found in Ludhiana as well [33], indicating the need to include brucellosis as a potential diagnosis in febrile cases with occupational risk factors.

The study shows how MCA can be used when data are collected on quite a large number of predictors and many of these are potentially related (weakly or strongly). In this context, it is useful to visualize these inter-relationships in order to get a better understanding of how farms could be grouped. The MCA identified a set of key variables which could be used to discriminate among farms, and these should be considered as important to collect information on in any future research undertaken in this region of India. Another methodological issue was presented because one site (Guwahati) had an extremely high herd prevalence of Brucella spp. compared to the other four sites. The strong collinearity between the outcome of interest (seropositivity against Brucella) and the site meant that the risk factor analyses could not utilize the full data set in one analysis. It would have been impossible to tell if any significant predictor was actually associated with Brucella spp. positivity or whether it just strongly differed between Guwahati and the other sites (with no effect on Brucella spp. risk). Consequently, risk factors were evaluated in Guwahati separately from the other study sites, which reduced the power of the study. For the four low-prevalence sites, there were only 14 positive farms (out of 362) while in Guwahati there were only 27 negative farms (out of 98). This lack of power limited our ability to identify risk factors for Brucella spp.

Raising awareness, training farmers, and modern techniques are often recommended for improving livestock disease control. In our study, the evidence for this was ambiguous. Guwahati, which had the highest prevalence in this study, was characterized by greater knowledge and higher use of modern animal health care inputs, such as vaccination and AI. On the other hand, hygiene appeared to be poor. Overall, a picture emerges of larger, less well managed herds with more reliance on vaccines and antibiotics for disease control. Other studies in Guwahati found that while training interventions had some impact on both hygiene and knowledge, there was no impact on the seropositivity for brucellosis [28]. This indicates caution in assuming intensification, even with improving knowledge and training, will lead to better disease control. It should be noted, however, that overall use of vaccination was low, indicating considerable scope for improvement. There seemed to be a high dependency on vaccinations in the face of outbreaks or when they were provided for free, with two of the sites having less than $3 \%$ of farms reporting routine vaccinations. Poor vaccination coverage 
can have different explanations, including poor access to vaccines, limited extension services, or poor understanding of farmers as to the benefits of using vaccines. In other studies in India, low knowledge about the function of vaccines and low willingness to pay has been associated with low uptake of vaccination $[34,35]$, which could possibly also explain the low adoption here. Studying the use of vaccines in chickens, it has been shown that having active support promotes vaccination and also makes people understand the function of vaccines better, which makes for more positive attitudes, and hence better uptake [36]. Even though farms that reported having used Brucella vaccines were excluded from analyses, it is possible that there might be farms where the farmer did not know which disease the animals were vaccinated against, which could have affected the results, but considering the low vaccination against Brucella overall, this is deemed a low risk. India has a government sponsored control program for brucellosis in cattle, with planned use of the S19 vaccine [31], but still vaccination is seldom performed in the field.

Many sero-surveys have been carried out for brucellosis in India, but these are typically conducted in one area, and differing methods make it hard to compare results from different areas, including the frequent targeting of animals with clinical symptoms [20]. Using the same, probabilistic study approach contemporaneously in five widely dispersed cities allowed us to confidently detect important and likely real differences between cities and to link this with some risk factors. An important finding of the study was that brucellosis can be very prevalent in some peri-urban areas and have very low presence in others. Moreover, disease transmission risk factors are different in scenarios with a high or a low infection pressure, and a habit, such as purchasing cows from neighbors is likely a protective factor when living in a low-risk area, but a high-risk practice in an area with a very high prevalence. Within Guwahati, the mixed effects model suggested a very high village level variance and a high intra-cluster correlation, indicating that future studies need to include as many villages as possible, which could be explained by the habit of purchasing animals from nearby farms, spreading the disease within a village, but less so between villages.

\section{Conclusions}

This study emphasizes the need to systematically identify disease hotspots for zoonotic diseases; the importance of considering intensifying peri-urban dairy belts in disease surveillance and control; the high degree to which structural factors may influence disease risk in peri-urban dairy, and the need for targeted, effective interventions. In light of the brucellosis control program in India, this study highlights the lack of sufficient vaccination coverage among smallholder dairy farmers in different parts of India, and also the high variability in prevalence. Knowledge about the prevalence in different areas can guide the control efforts, and improved information about local risk factors as well as the extent of farmers' understanding about the disease, can aid in creating better extension campaigns.

Author Contributions: J.F.L., M.K. \& D.G. conceptualized and designed the project, J.F.L. \& I.D. conducted the data analyses, J.S.B. \& J.P.S.G. conducted laboratory analyses, A.S.C., R.A.H., N.M.F. \& M.K. coordinated data collection, J.F.L. drafted the manuscript \& all authors contributed to critically revise the manuscript.

Funding: This study was part of a larger project supported by International Development Research Centre, Canada grant (No.107344-001). The project was also supported by the CGIAR Research Program for Nutrition and Health.

Acknowledgments: The authors would like to acknowledge all participating farmers, the data collection teams and other collaborators.

Conflicts of Interest: The authors declare no conflict of interest.

\section{References}

1. WHO FAO OIE; Corbel, M.J. Brucellosis in Humans and Animals; WHO: Rome, Italy, 2006.

2. Pappas, G.; Papadimitriou, P.; Akritidis, N.; Christou, L.; Tsianos, E.V. The new global map of human brucellosis. Lancet. Infect. Dis. 2006, 6, 91-99. [CrossRef]

3. OIE. Bovine Brucellosis: OIE Terrestrial Manual 2009; Office International de Epizootie: Paris, France, 2009. 
4. McDermott, J.J.; Grace, D.; Zinsstag, J. Economics of brucellosis impact and control in low-income countries. Sci. Tech. Rev. Off. Int. Des Epizoot. 2013, 32, 249-261. [CrossRef]

5. Godfroid, J.; Nielsen, K.; Saegerman, C. Diagnosis of brucellosis in livestock and wildlife. Croat. Med. J. 2010, 51, 296-305. [CrossRef] [PubMed]

6. OIE. Infection with Brucella abortus, Brucella melitensis and Brucella suis. In OIE Terrestrial Manual 2016; OIE (World Organisation for Animal Health): Rome, Italy, 2016.

7. Seleem, M.N.; Boyle, S.M.; Sriranganathan, N. Brucellosis: A re-emerging zoonosis. Vet. Microbiol. 2010, 140, 392-398. [CrossRef] [PubMed]

8. Millar, M.; Stack, J. Brucellosis-What every practitioner should know. Practice 2012, 34, 532-539. [CrossRef]

9. Delgado, C.L. Rising Consumption of Meat and Milk in Developing Countries Has Created a New Food Revolution. J. Nutr. 2003, 133, 3907S-3910S. [CrossRef]

10. FAOSTAT. Milk Total Production in India. 2015. Available online: http://faostat3.fao.org/browse/Q/QL/E (accessed on 12 April 2015).

11. Douphrate, D.I.; Hagevoort, G.R.; Nonnenmann, M.W.; Lunner Kolstrup, C.; Reynolds, S.J.; Jakob, M.; Kinsel, M. The dairy industry: A brief description of production practices, trends, and farm characteristics around the world. J. Agromed. 2013, 18, 187-197. [CrossRef] [PubMed]

12. Thumbi, S.M.; Njenga, M.K.; Marsh, T.L.; Noh, S.; Otiang, E.; Munyua, P.; Ochieng, L.; Ogola, E.; Yoder, J.; Audi, A.; et al. Linking Human Health and Livestock Health: A “One-Health" Platform for Integrated Analysis of Human Health, Livestock Health, and Economic Welfare in Livestock Dependent Communities. PLoS ONE 2015, 10, e0120761. [CrossRef]

13. Grace, D.; Wanyoike, F.; Lindahl, J.; Bett, B.; Randolph, T.; Rich, K.M. Poor livestock keepers: Ecosystem-poverty-health interactions. Philos. Trans. R. Soc. B-Econ. 2017, 372, 20160166. [CrossRef]

14. Omemo, P.; Ogola, E.; Omondi, G.; Wasonga, J.; Knobel, D. Knowledge, attitude and practice towards zoonoses among public health workers in Nyanza province, Kenya. J. Public Health Afr. 2012, 3, 22. [CrossRef]

15. de Glanville, W.A.; Conde-Álvarez, R.; Moriyón, I.; Njeru, J.; Díaz, R.; Cook, E.A.J.; Morin, M.; de, C.; Bronsvoort, B.M.; Thomas, L.F.; Kariuki, S.; et al. Poor performance of the rapid test for human brucellosis in health facilities in Kenya. PLoS Negl. Trop. Dis. 2017, 11, e0005508. [CrossRef]

16. Lindahl, J.F.; Vrentas, C.E.; Ram, P.; Deka, R.A.; Hazarika, H.; Rahman, R.G.; Bambal, J.S.; Bedi, C.; Pallab Chaduhuri, B.; Fairoze, N.M.; et al. Brucellosis in India: Results of a collaborative workshop to define One Health priorities. Trop. Anim. Health Prod. 2019. (submitted).

17. Lindahl, J.F.; Chauhan, A.; Gill, J.P.S.; Hazarika, R.A.; Fairoze, N.M.; Grace, D.; Kakkar, M. The extent and structure of peri-urban smallholder dairy farming in five cities in India. Trop. Anim. Health Prod. 2019. (submitted).

18. Emmerzaal, A.; de Wit, J.J.; Dijkstra, T.; Bakker, D.; van Zijderveld, F.G. The Dutch Brucella abortus monitoring programme for cattle: The impact of false-positive serological reactions and comparison of serological tests. Vet. Q. 2002, 24, 40-46. [CrossRef] [PubMed]

19. Gall, D.; Nielsen, K. Serological Diagnosis of Bovine Brucellosis: A Review of Test Performance and Cost Comparison. Rev. sci. tech. Off. int. Epiz. 2004, 23, 3. [CrossRef]

20. Deka, R.P.; Magnusson, U.; Grace, D.; Lindahl, J. Bovine brucellosis: Prevalence, risk factors, economic cost and control options with particular reference to India-A review. Infect. Ecol. Epidemiol. 2018, 8, 1556548. [CrossRef]

21. Makita, K.; Fèvre, E.M.; Waiswa, C.; Eisler, M.C.; Thrusfield, M.; Welburn, S.C. Herd prevalence of bovine brucellosis and analysis of risk factors in cattle in urban and peri-urban areas of the Kampala economic zone, Uganda. BMC Vet. Res. 2011, 7, 60. [CrossRef]

22. Mugizi, D.R.; Boqvist, S.; Nasinyama, G.W.; Waiswa, C.; Ikwap, K.; Rock, K.; Lindahl, E.; Magnusson, U.; Erume, J. Prevalence of and factors associated with Brucella sero-positivity in cattle in urban and peri-urban Gulu and Soroti towns of Uganda. J. Vet. Med. Sci. 2015, 77, 557-564. [CrossRef]

23. Gill, J.; Kaur, S.; Joshi, D.; Sharma, J. Epidemiological studies on brucellosis in farm animals in Punjab state of India and its public health significance. In Proceedings of the 9th International Symposium on Veterinary Epidemiology and Economics, Breckenridge, CO, USA, 6-11 August 2000.

24. Patel, M.; Patel, P.; Prajapati, M.; Kanani, A.N.; Tyagi, K.K.; Fulsoundar, A.B. Prevalence and risk factor's analysis of bovine brucellosis in peri-urban areas under intensive system of production in Gujarat, India. Vet. World 2014, 7, 509-516. [CrossRef] 
25. Aulakh, H.K.; Patil, P.K.; Sharma, S.; Kumar, H.; Mahajan, V.; Sandhu, K.S. A study on the epidemiology of bovine brucellosis in Punjab (India) using milk-ELISA. Acta Vet. Brno. 2008, 77, 393-399. [CrossRef]

26. Ul-Islam, M.R.; Gupta, M.P.; Filia, G.; Sidhu, P.K.; Shafi, T.A.; Bhat, S.A.; Hussain, S.A.; Mustafa, R.; Verma, A.K.; Sinha, D.K. Sero-epidemiology of brucellosis in organized cattle and buffaloes in Punjab (India). Adv. Anim. Vet. Sci. 2013, 1, 5-8.

27. Dhand, N.K.; Gumber, S.; Singh, B.B.; Aradhana; Bali, M.S.; Kumar, H.; Sharma, D.R.; Singh, J.; Sandhu, K.S. A study on the epidemiology of brucellosis in Punjab (India) using Survey Toolbox. Rev. Sci. Tech. 2005, 24, 879-885. [CrossRef]

28. Lindahl, J.F.; Deka, R.P.; Melin, D.; Berg, A.; Lundén, H.; Lapar, M.L.; Asse, R.; Grace, D. An inclusive and participatory approach to changing policies and practices for improved milk safety in Assam, northeast India. Glob. Food Sec. 2018, 17, 9-13. [CrossRef]

29. Chakraborty, M.; Patgiri, G.P.; Barman, N.N. Application of delayed-type hypersensitivity test (DTH) for the diagnosis of bovine brucellosis. Indian Vet. J. 2000, 77, 849-851.

30. Gogoi, S.B.; Hussain, P.; Sarma, P.C.; Barua, A.G.; Mahato, G.; Bora, D.P.; Konch, P.; Gogoi, P. Prevalence of bovine brucellosis in Assam, India. J. Entomol. Zool. Stud. 2017, 5, 179-185.

31. Renukaradhya, G.; Isloor, S.; Rajasekhar, M. Epidemiology, zoonotic aspects, vaccination and control/eradication of brucellosis in India. Vet. Microbiol. 2002, 90, 183-195. [CrossRef]

32. Hussain, S.A.; Rahman, H.; Pal, D.; Ahmed, K. Sero-prevalence of bovine and human brucellosis in Assam. Indianj. Comp. Microbiol. Immunol. Infect. Dis. 2000, 21, 165-166.

33. Yohannes Gemechu, M.; Paul Singh Gill, J. Seroepidemiological survey of human brucellosis in and around Ludhiana, India. Emerg. Health Threat. J. 2011, 4, 1-7. [CrossRef]

34. Heffernan, C.; Thomson, K.; Nielsen, L. Caste, livelihoods and livestock: An exploration of the uptake of livestock vaccination adoption among poor farmers in India. J. Int. Dev. 2011, 23, 103-118. [CrossRef]

35. Basunathe, V.K.; Sawarkar, S.W.; Sasidhar, P.V.K. Adoption of Dairy Production Technologies and Implications for Dairy Development in India. Outlook Agric. 2010, 39, 134-140. [CrossRef]

36. Lindahl, J.F.; Young, J.; Wyatt, A.; Young, M.; Alders, R.; Bagnol, B.; Kibaya, A.; Grace, D. Do vaccination interventions have effects? A study on how poultry vaccination interventions change smallholder farmer knowledge, attitudes, and practice in villages in Kenya and Tanzania. Trop. Anim. Health Prod. 2018, 51, 213-220. [CrossRef] [PubMed] 